\title{
Effect of Treatment Regimen on Long-Term Mortality of Geriatric Patients Diagnosed With Stable Coronary Artery Disease
}

\author{
Uğur Küçük $^{1}$, Ali Duygu ${ }^{2}$, Bahadır Kırılmaz ${ }^{1}$ \\ 1. Cardiology, Canakkale Onsekiz Mart University Faculty of Medicine, Çanakkale, TUR 2. Cardiology, Canakkale \\ Onsekiz Mart University Faculty of Medicıne, Çanakkale, TUR
}

Corresponding author: Uğur Küçük, drugurkucuk@hotmail.com

\section{Abstract \\ Background}

Increased life expectancy across the world has resulted in an increase in the proportion of the elderly population who are lost to heart diseases. Advanced age and comorbidities are believed to change the response to treatments. In this study, we aimed to investigate the effects of surgical and medical treatments on the mortality of stable coronary diseases.

\section{Methods}

A total of 150 geriatric patients who underwent coronary angiography (CAG) were followed up in our cardiology clinic. Patients who decided to undergo coronary artery bypass graft (CABG) surgery after CAG and were willing to undergo the operation were assigned to group 1 , whereas those who were unwilling to undergo the operation were not eligible for percutaneous coronary intervention and were followed up medically, and were assigned to group 2 . Keeping the primary goal as mortality rates, both the groups were compared using medical records for three years after the treatment.

\section{Results}

After three years, the overall mortality rate included six patients (16\%) in the CABG group versus 63 patients $(55 \%)$ in the medical therapy group $(\mathrm{p}<0.001)$. The CABG therapy was found to be significantly and independently associated with first- and third-year mortality (risk ratio: $0.064,95 \%$ confidence interval: $0.009-0.467, \mathrm{p}=0.007$; risk ratio: $0.305,95 \%$ confidence interval: $0.151-0.615, \mathrm{p}<0.001$, respectively). Kaplan-Meier analysis for first- and third-year all-cause mortality rates led to significant results and curves between the groups.

\section{Conclusion}

Review began 02/14/2021 Review ended 02/15/2021 Published 02/28/2021

\section{() Copyright 2021}

Küçük et al. This is an open access article distributed under the terms of the Creative Commons Attribution License CC-BY 4.0., which permits unrestricted use, distribution, and reproduction in any medium, provided the original author and source are credited.
Our study revealed that compared to CABG surgery in the treatment of coronary artery disease in geriatric patients, medical treatment is associated with poor outcomes in terms of mortality in long-term follow-up.

Categories: Cardiac/Thoracic/Vascular Surgery, Cardiology, Public Health

Keywords: geriatric, mortality, coronary artery bypass graft surgery

\section{Introduction}

Coronary artery disease (CAD) is an important cause of morbidity and mortality, especially in the elderly, as also in adults [1]. Advances in healthcare have resulted in an increase in life expectancy and an increase in the number of hospital admissions for elderly individuals in need of medical care. Since risk factors such as hypertension (HT), diabetes mellitus (DM), and obesity are more common in advanced ages, an increase in the prevalence of CAD has been observed worldwide [2].

Comorbid conditions, deterioration in cognitive functions, and atypical observation or late onset of symptoms in patients may cause some delays in treatment. While the guideline recommendations are mostly aimed at individuals under the age of 75 years, the underrepresentation of individuals of age $>75$ years in studies has led to a lack of opinion on the diagnosis and treatment of diseases, as frequently observed in older ages [3].

In geriatric patients, personalized treatment regimens are prominent due to factors such as the patient's biological age, comorbid conditions, and intolerance to the applied treatment [4]. Risk scores such as Syntax, Gensini, and Grace, which are used in treatment management after coronary angiography (CAG), are used in patients diagnosed with CAD [5]. Several studies have suggested that the choice of an effective treatment method can reduce mortality and morbidity [6]. However, the ages of the patients have not been taken into 
consideration in the previous studies [7].

In our study, we aimed to investigate the importance of the treatment regimen to be selected and its effect on the mortality rate, irrespective of the age at which the treatment decisions of geriatric patients with stable CAD were taken.

\section{Materials And Methods}

The study included 150 patients of age $>75$ years who had three-vessel coronary artery stenosis in CAD and were hospitalized with the diagnosis of CAD between November 2009 and February 2018 at the cardiology clinic of the university hospital. Medical records include documentation of patient's history, clinical findings, diagnostic test results, operation notes, and death. In this retrospective study, the patients were divided into two groups. Group 1 included 38 patients who underwent coronary artery bypass operation. Group 2 included 112 patients who were offered coronary artery bypass surgery but refused to undergo the same. They were at high risk for percutaneous coronary intervention but did not accept interventional treatment and received medical treatment. Laboratory and CAG data were evaluated for both groups. The mortality rates in the two groups were compared using medical records during the one- and threeyear follow-up period after angiography. The hemogram, lipid panel, and kidney function tests of all the patients were obtained from the patient's medical file archive.

\section{Exclusion Criteria}

Patients of age $<75$ years who had chronic renal failure, acute coronary syndrome, active infection, malignant disease, cerebrovascular disease, and coronary artery bypass surgery, those who were scheduled for serious valve surgery, and those who had contraindications but did not accept CAG were not included in the study.

Before initiating the study, approval was obtained from the local ethics committee of the hospital, in line with the recommendations of the Declaration of Helsinki (Decision no: 2020-12).

\section{Coronary Angiography and Calculation of Syntax Score}

The standardized Judkins technique was used while CAG was performed through the femoral or radial arteries. At least two different image recordings were evaluated while deciding on the severity of the coronary artery. Lesions of $\geqslant 50 \%$ in at least one coronary artery were accepted as significant stenosis. The Syntax score was calculated using the most recent system (www.syntaxscore.com) for vessels with stenosis and diameter $\geqslant 1.5 \mathrm{~mm}$ above the p-value [8]. Two experienced cardiologists evaluated the angiography images of the patients and calculated their Syntax scores.

\section{Statistical Analyses}

SPSS 21.0 (SPSS Inc., Chicago, IL, USA) software was used for statistical analyses. Whether the variables fit the normal distribution was evaluated using the Kolmogorov-Smirnov test. While continuous variables were expressed as mean \pm standard deviation, categorical variables were expressed as percent and numbers. A chisquare test was used to compare the probability ratios of categorical variables. Mann-Whitney's U-test was used for data that did not show normal distribution. The Kaplan-Meier curves were used to indicate death in two patient groups, as defined in the medical and coronary artery bypass graft (CABG) treatment groups. Logistic regression analysis was performed to determine the effect of variables. In addition, 95\% confidence intervals were calculated with standardized beta coefficients, and a p-value $<0.05$ was considered to be statistically significant.

\section{Results}

The basic clinical characteristics, laboratory values, and pre-admission medications of the patient groups we enrolled in the study are listed (Table 1). The mean age of the patients included in the study was $79 \pm 3$ years. Of the 150 patients, 91 were men, and 59 were women. Only 38 of the geriatric patients were operated on, and 112 patients were followed up medically. The mean Syntax risk score was $24 \pm 6$, and there was no statistically significant difference between the groups $(\mathrm{p}=0.290$; Table 1$)$. The echocardiographic data of the patients at the time of admission were not significantly different between the groups $(\mathrm{p}=0.081$; Table 1$)$. Operation data are reported in Table 1 . Cross-clamping time was $74.6 \pm 6.92$ minutes and cardiopulmonary bypass time was $112.43 \pm 16.91$ minutes. The median length of stay in intensive care unit was 7 days. The median intubation time was 26 hours. Postoperative resternotomy occurred in three patients due to tamponade. Blood transfusion was done in four patients. There were no in-hospital deaths in the on-pump $\mathrm{CABG}$ group. The mortality rate in the medical treatment group was statistically higher than in the CABG group $(\mathrm{p}<0.001$; Table 1). In univariate and multivariate logistic regression analyses, an independent relationship was established between the hemoglobin levels of the patients and the preferred treatment method (on-pump CABG) and first- and third-year mortality (Tables 2 and 3). The Kaplan-Meier analysis was performed for all-cause mortality at first and third years of patients with advanced-age stable CAD in medical and CABG treatments, with significant results $(\mathrm{p}<0.001$; Figures 1,2$)$. 


\section{Cureus}

\begin{tabular}{|c|c|c|c|}
\hline Variables & $\operatorname{CABG}(n=38)$ & Medical therapy $(n=112)$ & $p$ \\
\hline Age (years) & $78.8 \pm 3.3$ & $79.1 \pm 3.1$ & 0.623 \\
\hline Female n (\%) & $15(10)$ & $44(29.3)$ & 0.984 \\
\hline HT $n(\%)$ & $24(16)$ & $60(40)$ & 0.304 \\
\hline DMn (\%) & $10(6.7)$ & 35 (23.3) & 0.566 \\
\hline Systolic blood pressure (mmHg) & $133.68 \pm 9.13$ & $133.15 \pm 9.40$ & 0.794 \\
\hline Diastolic blood pressure (mmHg) & $77.32 \pm 6.48$ & $77.17 \pm 7.58$ & 0.925 \\
\hline Current smoker n (\%) & $13(8.7)$ & 58 (38.7) & 0.061 \\
\hline Serum glucose (mg/dL) & $127.42 \pm 32.15$ & $126.31 \pm 32.40$ & 0.855 \\
\hline Creatinine (mg/dL) & $0.97 \pm 0.27$ & $1.11 \pm 0.40$ & 0.133 \\
\hline TSH (mU/L) & $0.57 \pm 0.43$ & $1.76 \pm 0.88$ & 0.078 \\
\hline LDL-C (mg/dL) & $120.29 \pm 33.79$ & $128.09 \pm 39.09$ & 0.148 \\
\hline Hemoglobin (g/dL) & $12.18 \pm 1.81$ & $12.20 \pm 1.84$ & 0.795 \\
\hline WBC count $\left(\times 10^{3} / / \mathrm{LL}\right)$ & $7.76 \pm 2.10$ & $8.19 \pm 2.37$ & 0.401 \\
\hline Neutrophil count $\left(\times 10^{3} / \mathbf{L}\right)$ & $5.14 \pm 2.51$ & $5.22 \pm 2.31$ & 0.803 \\
\hline Lymphocyte count $\left(\times 10^{3} / L\right)$ & $1.74 \pm 0.53$ & $1.71 \pm 0.59$ & 0.927 \\
\hline Thrombocyte count $\left(x 10^{3} / \mu L\right)$ & $225.07 \pm 68.84$ & $223.99 \pm 73.04$ & 0.936 \\
\hline LVEF $(\%)$ & $50.92 \pm 8.5$ & $48 \pm 8.9$ & 0.081 \\
\hline Syntax score & $23.24 \pm 6.10$ & $24.48 \pm 6.29$ & 0.290 \\
\hline \multicolumn{4}{|l|}{ Medication n (\%) } \\
\hline ASA & $28(18.7)$ & $85(56.7)$ & 0.785 \\
\hline ACEI/ARB & $24(16)$ & 60 (40) & 0.304 \\
\hline Beta blocker & $5(12.5)$ & $14(35)$ & 0.873 \\
\hline Statin & $6(4)$ & 25 (16.7) & 0.390 \\
\hline Mean of death (year) & $2.6 \pm 0.7$ & $1.7 \pm 1.1$ & $<0.001$ \\
\hline Time of CPB (minutes) & $112.43 \pm 16.91$ & & \\
\hline Duration of cross-clamping (minutes) & $74.6 \pm 6.92$ & & \\
\hline IT (hours) & $26(2-55)$ & & \\
\hline ICU stay (days) & $7(3-12)$ & & \\
\hline \multicolumn{4}{|l|}{ Mortality n (\%) } \\
\hline 1 year & $1(2.6)$ & 38 (33.9) & $<0.001$ \\
\hline 1-3 years & $5(13.5)$ & $25(33.8)$ & 0.023 \\
\hline
\end{tabular}

TABLE 1: Baseline clinical characteristics, laboratory values, and preadmission medications of the patients

CABG: coronary artery bypass grafting; WBC: white blood cell; DM: diabetes mellitus; HT: hypertension; LVEF: left ventricle ejection fraction; ACEI: angiotensinogen-converting enzyme inhibitor; ARB: angiotensin receptor blocker; ASA: acetylsalicylic acid; LDL-C: low-density lipoprotein cholesterol; Syntax: the synergy between percutaneous coronary intervention with taxus and cardiac surgery; LDL: low-density lipoprotein; CPB: cardiopulmonary bypass; IT: intubation time; ICU: intensive care unit 


\section{Cureus}

\begin{tabular}{|c|c|c|c|c|c|c|}
\hline \multirow[b]{2}{*}{ Variables } & \multicolumn{3}{|c|}{ Univariate } & \multicolumn{3}{|c|}{ Multivariate } \\
\hline & $\mathrm{p}$ & $\mathrm{HR}$ & $95 \% \mathrm{Cl}$ & $p$ & $\mathrm{HR}$ & $95 \% \mathrm{Cl}$ \\
\hline Age & 0.520 & 1.032 & 0.938-1.1.135 & & & \\
\hline Syntax score & 0.358 & 1.024 & 0.973-1.077 & & & \\
\hline Diabetes mellitus & 0.301 & 1.481 & 0.703-3.120 & & & \\
\hline Hypertension & 0.830 & 1.072 & 0.569-2.019 & & & \\
\hline Hemoglobin levels & 0.035 & 0.828 & 0.696-0.987 & 0.027 & 0.824 & 0.694-0.979 \\
\hline Creatinine & 0.746 & 0.835 & $0.281-0.084$ & & & \\
\hline Serum glucose & 0.772 & 0.999 & 0.989-1.009 & & & \\
\hline LDL-C & 0.286 & 1.004 & 0.996-1.012 & & & \\
\hline Usage of beta blocker & 0.815 & 0.927 & 0.492-1.746 & & & \\
\hline Usage of ACE/ARB & 0.830 & 0.933 & 0.495-1.757 & & & \\
\hline Usage of ASA & 0.960 & 0.982 & 0.478-2.014 & & & \\
\hline Usage of statin & 0.993 & 0.996 & 0.458-2.168 & & & \\
\hline Treatment method (CABG) & 0.007 & 0.065 & $0.009-0.475$ & 0.007 & 0.064 & 0.009-0.467 \\
\hline
\end{tabular}

TABLE 2: Univariate and multivariate cox regression analyses for predicting first-year mortality

Multivariate Cox proportional-hazards model including the variables in univariate analysis and also variables found to be significantly different between groups I and II with forward stepwise method.

$\mathrm{Cl}$ : confidence interval; HR: hazard ratio; LDL-C, low-density lipoprotein cholesterol; ACEI, angiotensinogen-converting enzyme inhibitor; ARB, angiotensin receptor blocker; ASA, acetylsalicylic acid; CABG, coronary artery bypass grafting 


\section{Cureus}

\begin{tabular}{|c|c|c|c|c|c|c|}
\hline \multirow[b]{2}{*}{ Variables } & \multicolumn{3}{|c|}{ Univariate } & \multicolumn{3}{|c|}{ Multivariate } \\
\hline & $\mathrm{p}$ & $\mathrm{HR}$ & $95 \% \mathrm{Cl}$ & $\mathrm{p}$ & $\mathrm{HR}$ & $95 \% \mathrm{Cl}$ \\
\hline Age & 0.311 & 1.038 & 0.966-1.1116 & & & \\
\hline Syntax score & 0.541 & 0.988 & 0.951-1.027 & & & \\
\hline Diabetes mellitus & 0.472 & 1.214 & $0.717-2.055$ & & & \\
\hline Hypertension & 0.625 & 1.124 & 0.703-1.798 & & & \\
\hline Creatinine & 0.498 & 0.738 & $0.307-1.775$ & & & \\
\hline Serum glucose & 0.880 & 0.999 & 0.992-1.007 & & & \\
\hline Hemoglobin levels & 0.043 & 0.875 & 0.770-0.096 & 0.028 & 0.866 & 0.762-0.0984 \\
\hline LDL-C & 0.183 & 1.004 & $0.998-1.010$ & & & \\
\hline Usage of beta blocker & 0.648 & 0.895 & $0.558-1.438$ & & & \\
\hline Usage of ACE/ARB & 0.830 & 0.933 & $0.495-1.757$ & & & \\
\hline Usage of ASA & 0.811 & 0.938 & 0.554-1.588 & & & \\
\hline Usage of statin & 0.603 & 0.852 & 0.467-1.557 & & & \\
\hline Method of treatment (CABG) & 0.001 & 0.314 & $0.156-0.633$ & 0.001 & 0.305 & $0.151-0.615$ \\
\hline
\end{tabular}

TABLE 3: Univariate and multivariate cox regression analyses for predicting third-year mortality

Multivariate Cox proportional-hazards model including the variables in univariate analysis and also variables found to be significantly different between groups I and II with forward stepwise method.

$\mathrm{Cl}$ : confidence interval; HR: hazard ratio; LDL-C: low-density lipoprotein cholesterol; ACEI: angiotensinogen-converting enzyme inhibitor; ARB: angiotensin receptor blocker; ASA: acetylsalicylic acid; CABG: coronary artery bypass grafting

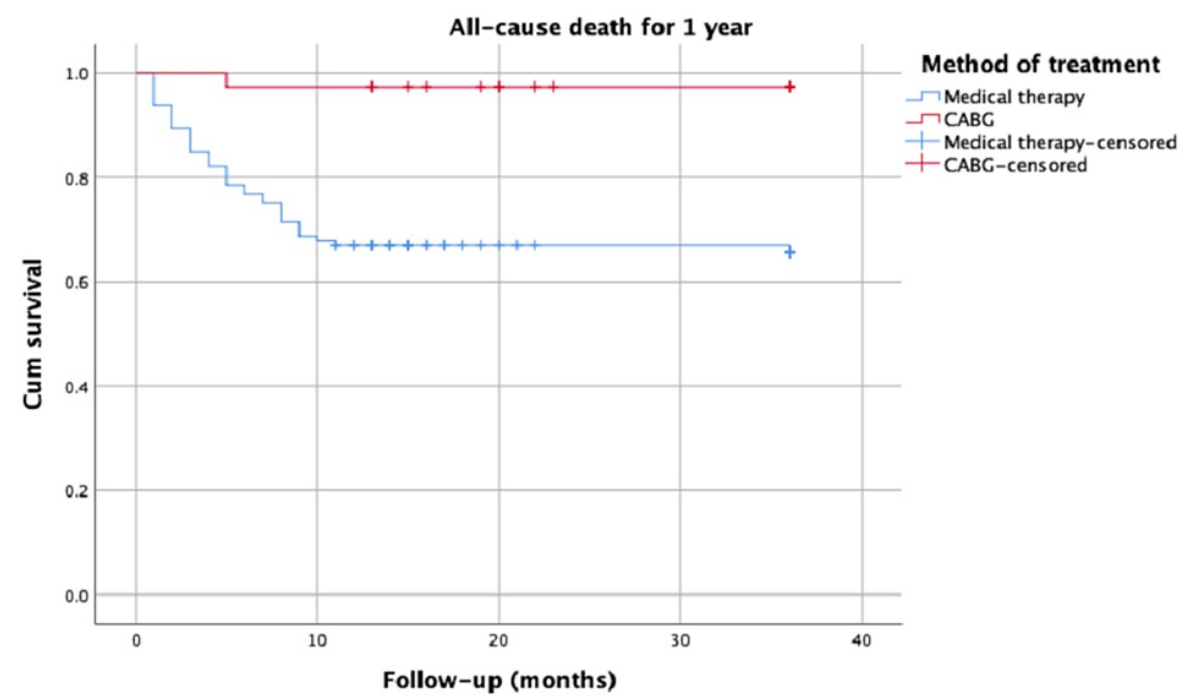

FIGURE 1: Kaplan-Meier analysis for all-cause mortality at first year CABG: coronary artery bypass grafting 


\section{Cureus}

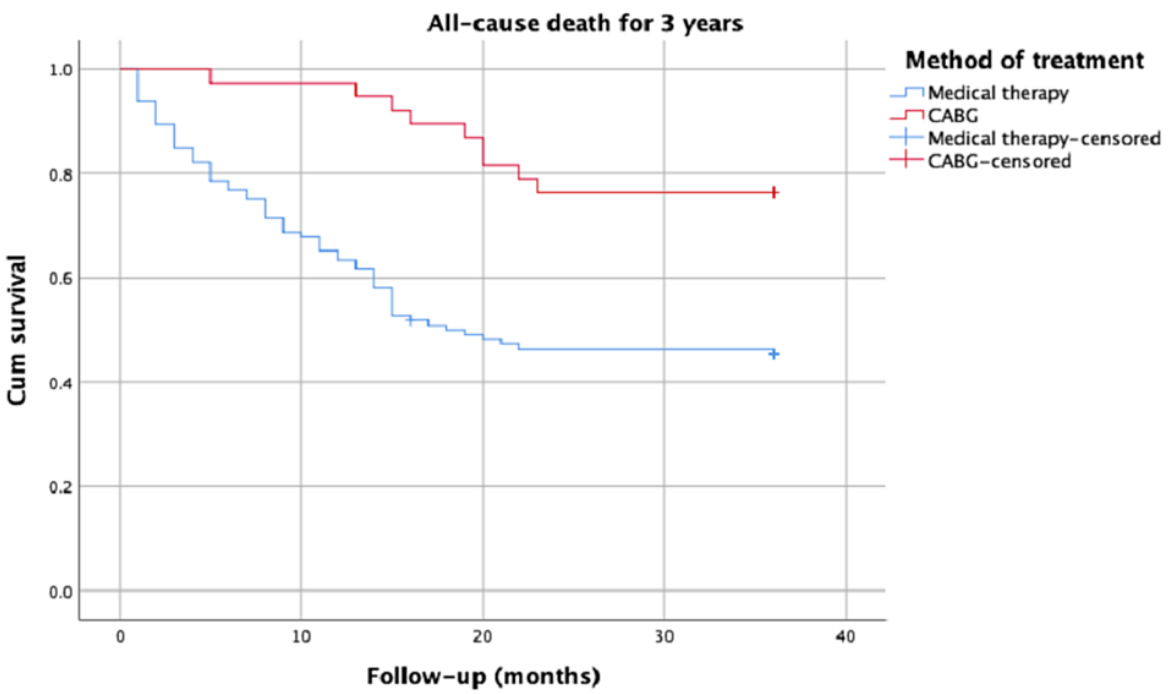

FIGURE 2: Kaplan-Meier analysis for all-cause mortality at third year

CABG: coronary artery bypass grafting

\section{Discussion}

Cardiovascular diseases top the list among the causes of death across the world. The main form of cause is atherosclerosis, and there may be various endpoints such as $\mathrm{CAD}$, cerebrovascular diseases, or peripheral or carotid artery diseases [9].

As a result of the three-year follow-up in our study, we demonstrated that the prognosis of patients who underwent surgery was better than that of the medical group, where long-term follow-up of advanced-age patients diagnosed with stable CAD was undertaken.

As per the current guideline recommendation, the main purpose of treatment in patients with stable CAD is to prolong their life span, and the preference for surgery is low due to the presence of multivessel diseases in angiography performed in geriatric patients and the accompanying comorbid conditions, which is why medical or percutaneous coronary interventional procedures are more preferred [10]. In the Courage study, no differences were noted in terms of cardiac events between the groups that underwent medical treatment and percutaneous coronary intervention in patients diagnosed with chronic stable CAD of age $>65$ years [11].

The effect of invasive treatment on survival was statistically similar when compared to the medical treatment performed by Matthias et al. in geriatric patients of an average age of 80 years [12]. In another study, Azin et al. conducted long-term follow-ups in which chest pain and functional capacity were positively affected in the operated group of advanced-age patients who underwent CABG operation and who received medical treatments. The authors demonstrated that mortality rates after one month were similar between the groups [13]. Unlike in all these past studies, in the Kaplan-Meier statistical analyses performed for all-cause mortality in our study, geriatric patients showed better survival rates for both short-term oneyear and long-term three-year survival analyses in the group that had the CABG operation.

Left ventricular ejection fraction (LVEF) is recognized as a strong predictor of survival in patients with cardiovascular diseases [14]. While the differences obtained in the studies performed were interpreted as being related to accompanying clinical manifestations (such as HT and DM) and the differences in LVEF, no differences were noted between the groups for the variables specified in our study $[15,16]$.

Syntax score, which is frequently used for treatment preferences after CAG, provides important information, especially in multivessel diseases, main coronary lesions, and complex cases [17]. Percutaneous coronary intervention or surgery as a treatment option, when performed according to the Syntax score in advanced age, provides a significant reduction in morbidity and mortality. In the study conducted by Madeleine et al., the Syntax score predicted the risk of death in patients of age $>75$ years in stable and unstable patients, limited to 1 year [18]. In the three-year follow-up in our study, the Syntax score was not useful in predicting the risk of death among the advanced-age treatment groups. Contrary to that in past studies, the Syntax score was calculated in our study by only looking at the coronary anatomy in elderly patients, which is not sufficient, necessitating making a personalized decision by evaluating other accompanying clinical 
manifestations.

The most significant limitation of our study is that it is a single-center and retrospective study. Another limitation is the small number of individuals included in our study, and the most important reason for this is that the desired data could not be accessed. However, the prospective follow-up of a large number of patients of age $>75$ years who had undergone CABG or medical treatment is difficult and a time-consuming task.

\section{Conclusions}

In conclusion, considering the technological methods developed in the field of coronary artery bypass surgery and the experience of the surgical team, it should be kept in mind that surgical treatment positively affects long-term outcomes when compared to medical treatments provided to geriatric patients.

\section{Additional Information}

\section{Disclosures}

Human subjects: Consent was obtained or waived by all participants in this study. Clinical Research Ethics Committee, Çanakkale Onsekiz Mart University Rectory issued approval 2011-KAEK-27/2020-E.2000140296. Karar Tarihi: 23.09.2020 Karar No: 2020-12 Karar-20/2011-KAEK-27/2020-E.2000140296no'lu araştırma ile ilgili olarak, Proje yürütücüsü Dr. Öğr. Üyesi Uğur KÜÇÜK'ün çalışması Etik Kurul tarafından değerlendirilmiş olup; yapılan oylamada "ETIK KURUL ONAYINI ALIR" kararı verilmiştir. Animal subjects: All authors have confirmed that this study did not involve animal subjects or tissue. Conflicts of interest: In compliance with the ICMJE uniform disclosure form, all authors declare the following: Payment/services info: All authors have declared that no financial support was received from any organization for the submitted work. Financial relationships: All authors have declared that they have no financial relationships at present or within the previous three years with any organizations that might have an interest in the submitted work. Other relationships: All authors have declared that there are no other relationships or activities that could appear to have influenced the submitted work.

\section{References}

1. Benjamin EJ, Blaha MJ, Chiuve SE, et al.: Heart disease and stroke statistics-2017 update: a report from the American Heart Association. Circulation. 2017, 135:e146-e603. 10.1161/CIR.0000000000000485

2. Fried LF, Shlipak MG, Crump C, et al.: Renal insufficiency as a predictor of cardiovascular outcomes and mortality in elderly individuals. J Am Coll Cardiol. 2003, 41:1364-1372. 10.1016/s0735-1097(03)00163-3

3. Raja SG: Myocardial revascularization for the elderly: current options, role of off-pump coronary artery bypass grafting and outcomes. Curr Cardiol Rev. 2012, 8:26-36. 10.2174/157340312801215809

4. Alexander KP, Newby LK, Armstrong PW, et al.: Acute coronary care in the elderly, part II: ST-segmentelevation myocardial infarction: a scientific statement for healthcare professionals from the American Heart Association Council on Clinical Cardiology: in collaboration with the Society of Geriatric Cardiology. Circulation. 2007, 115:2570-2589. 10.1161/CIRCULATIONAHA.107.182616

5. The TIME investigators: Trial of invasive versus medical therapy in elderly patients with chronic symptomatic coronary-artery disease (TIME): a randomised trial. Lancet. 2001, 358:951-957. 10.1016/S01406736(01)06100-1

6. Kaiser C, Kuster G, Erne P, et al.: Risks and benefits of optimized medical and revascularisation therapy in elderly patients with angina: on-treatment analysis of the TIME trial. Eur Heart J. 2004, 25:1036-1042. 10.1016/j.ehj.2004.02.033

7. Reynolds HR, Hochman JS: Cardiogenic shock: current concepts and improving outcomes. Circulation. 2008, 117:686-697. 10.1161/CIRCULATIONAHA.106.613596

8. Serruys PW, Onuma Y, Garg S, et al.: Assessment of the SYNTAX score in the Syntax study . EuroIntervention. 2009, 5:50-56. 10.4244/eijv5i1a9

9. Virmani R, Kolodgie FD, Burke AP, Farb A, Schwartz SM: Lessons from sudden coronary death: a comprehensive morphological classification scheme for atherosclerotic lesions. Arterioscler Thromb Vasc Biol. 2000, 20:1262-1275. 10.1161/01.atv.20.5.1262

10. Knuuti J, Wijns W, Saraste A, et al.: 2019 ESC guidelines for the diagnosis and management of chronic coronary syndromes. Eur Heart J. 2020, 41:407-477. 10.1093/eurheartj/ehz425

11. Teo KK, Sedlis SP, Boden WE, et al.: Optimal medical therapy with or without percutaneous coronary intervention in older patients with stable coronary disease: a pre-specified subset analysis of the COURAGE (Clinical Outcomes Utilizing Revascularization and Aggressive druG Evaluation) trial. J Am Coll Cardiol. 2009, 54:1303-1308. 10.1016/j.jacc.2009.07.013

12. Pfisterer M, Trial of Invasive versus Medical therapy in Elderly Patients Investigators: Long-term outcome in elderly patients with chronic angina managed invasively versus by optimized medical therapy: four-year follow-up of the randomized Trial of Invasive versus Medical therapy in Elderly patients (TIME). Circulation. 2004, 110:1213-1218. 10.1161/01.CIR.0000140983.69571.BA

13. Alizadehasl A, Sohrabi B, Panjavi L, et al.: Comparison of the effects of coronary artery bypass grafting versus medical therapy on short and long term outcomes in octogenarian patients with multi-vessel coronary artery disease. Res Cardiovasc Med. 2016, 5:e30590. 10.5812/cardiovascmed.30590

14. Velazquez EJ, Williams JB, Yow E, et al.: Long-term survival of patients with ischemic cardiomyopa- thy treated by coronary artery bypass grafting versus medical therapy. Ann Thorac Surg. 2012, 93:523-530. 10.1016/j.athoracsur.2011.10.064 


\section{Cureus}

15. O'Connor CM, Velazquez EJ, Gardner LH, et al.: Comparison of coronary artery bypass grafting versus medical therapy on long-term outcome in patients with ischemic cardiomyopathy (a 25-year experience from the Duke Cardiovascular Disease Databank). Am J Cardiol. 2002, 90:101-107. 10.1016/s00029149(02)02429-3

16. Alexander KP, Anstrom KJ, Muhlbaier LH, et al.: Outcomes of cardiac surgery in patients $>$ or $=80$ years: results from the National Cardiovascular Network. J Am Coll Cardiol. 2000, 35:731-738. 10.1016/s07351097(99)00606-3

17. Bundhun PK, Sookharee Y, Bholee A, Huang F: Application of the SYNTAX score in interventional cardiology: a systematic review and meta-analysis. Medicine (Baltimore). 2017, 96:e7410. 10.1097/MD.0000000000007410

18. Eickhoff M, Schüpke S, Khandoga A, et al.: Age-dependent impact of the SYNTAX-score on longer-term mortality after percutaneous coronary intervention in an all-comer population. J Geriatr Cardiol. 2018, 15:559-566. 10.11909/j.issn.1671-5411.2018.09.009 